\title{
Multi-Functional Technical Devices for Improvement and Control of Athletes' Preparedness in Martial Arts
}

\author{
Olha Zadorozhna', Yuriy Briskin', Maryan Pityn', Serhiy Smyrnovskyy', Zoryana Semeryak ${ }^{2}$ Ivan Khomiak ${ }^{1}$ \\ and Ivan Hlukhov ${ }^{3}$
}

${ }^{1}$ Lviv State University of Physical Culture, Department of Theory of Sports and Physical Culture, Lviv, Ukraine, ${ }^{2}$ Lviv State University of Physical Culture, Department of Fencing, Boxing and National Martial Arts, Lviv, Ukraine, ${ }^{3}$ Kherson State University, Department of Medical and Biological Foundations of Physical Education and Sports, Kherson, Ukraine

\begin{abstract}
The present work studied specifics of technical devices for the improvement and control of athletes' preparedness in martial arts. Their use is aimed at the improvement of different sides of athletes' preparedness, including technical and tactical skills, and theoretical knowledge. The main advantage of the devices is the opportunity not only to develop sports skills but also to have operational feedback between the athlete and the coach or team partner in real time. Three multi-functional technical devices were created: "TTT", "Cube", and "Device for the technical training of fencers". Their efficiency was estimated with two pedagogical experiments involving 52 young epee and foil fencers (age 11-15 years) and 45 epee fencers (age 11-15 years). The results of the first pedagogical experiments illustrated that the use of "TTT" simulator enabled increasing the sportsmen's level of knowledge at $48.3 \%-145.5 \%(p<0.05)$. The results of the second pedagogical experiments illustrated that the use of "Device for the technical training of fencers" enabled increasing the sportsmen's technical preparedness $(\mathrm{p}<0.01)$.
\end{abstract}

Keywords: technical devices, knowledge, tactical skills, competition, preparedness

\section{Introduction}

The evolution of competitive activity in martial sports identifies changes in training systems (Alekseenko, 1970; Bychkov, 2006; Harmenberg, 2007). The current development of fencing, boxing, wrestling, judo and other sports could be characterized by the intensification of competitive activity, changes in competition rules, and the improvement of various aspects of the training of experienced athletes (Jean-Marie, 2008; Johnson, 2016, 2017; Chen et al., 2017). Current trends in martial sports illustrate that the winner of different competitions is the person or team who quickly and effectively introduces new scientific developments and appropriately responds to evolutionary changes in the sport by the correction of individual aspects of athletes' training, including technical, tactical, and theoretical aspects (Matveev, 2001; Lisitsyn, 2015; Kriventsova, Iermakov, Bartik, Nosko, \& Cynarski, 2017; Johnson \& Kang, 2018; Briskin, Pityn, Zadorozhna, \& Khomiak, 2018). Moreover, the high level of tactical skills is impossible without an extensive technical arsenal and the skills to perform technical actions in their application in competition. Technical training provides a platform for the further improvement of tactical skills and achieving a high level of technical and tactical skills (Tupeev \& Bojko, 2010; Saenko, Ivanov, \& Stepanenko, 2011; Ryzhkova, 2014). Thus, to achieve a high level of technical and tactical skills, sportsmen ought to use effective technical devices.

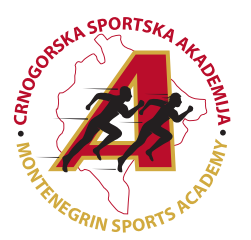

Correspondence:

O. Zadorozhna

Lviv State University of Physical Culture, Department of Theory of Sports and Physical Culture, Kostyushko, 11, Lviv, Ukraine

E-mail: ozadorozhna@ukr.net 
Analysis of recent research and publications illustrates that researchers in martial arts have been focused on issues of technical and tactical training, physical skills and their indicators, psychological aspects of training, and the formation of special knowledge (Pityn et al., 2017; Lisitsyn, 2015; Kriventsova et al., 2017; Johnson \& Kang, 2018). At the same time, various technical devices have been developed and implemented, a great many of which enable using modern interactive technologies for the formation of tactical thinking of athletes, based on the receipt of operational feedback between the athlete and the trainer/partner on a team in real time, which leads to the development of technical skills (Harmenberg, Ceci, Barvestad, Hjerpe, \& Nyström, 1991; Shevchuk, 2009; Johnson, 2016); others are devoted to the control and improvement of physical skills. In recent years, methods of technical and tactical training aimed at improving motor actions and solving situational tasks of competitive activity have been invented (Saenko et al., 2011; Ryzhkova, 2014; Kriventsova et al., 2017; Velychenko \& Zherdzinsky, 2017).

The generalization of the scientific results gives the opportunity to make a conclusion about the objective of researchers in using universal or multi-functional devices that allow solving a wide range of tasks simultaneously or sequentially (for example, to formulate relevant knowledge, skills and abilities, and to control them using the same tools).

Based on all the above, the objective of this study is dual. First, there is a need to develop new effective devices for the improvement of athletes' preparedness, especially technical and tactical. Second, all of these means should be multi-functional and allow controlling various parameters of preparedness and require a minimum amount of time to use them.

\section{Methods}

Our research included few stages and was devoted to devel- oping and implementing several technical devices in martial arts. Theoretical analysis and generalization were used during work with literary sources on the problems of the research and identification of the main problems of technical and tactical training in fencing. A documentary method was used for the analysis of official documents of the International Federation of Fencing (FIE), the National Federation of Fencing of Ukraine, fencing programmes for youth and other documents.

Pedagogical observation was used to determine the arsenal of technical and tactical actions of highly experienced epee fencers. It was made by using official video of fencing bouts of FIE. One hundred bouts of epee fencers who took part in the World Cup, World Championships, and Olympic Games (seasons 2015-2016) were analysed. The scope and efficiency of technical and tactical actions were determined, taking into account ways of weapon control (in our paper, "weapon control" means the way of managing the weapon using two types of handles: a smooth one or a pistol grip). That information was used for constructing an experimental program.

Two surveys were also made. The first (2012-2013) was aimed at determining the significance of the formation of knowledge on different informational blocks (including technique and tactics) in fencing and the use of different methods for their study. The second (2015-2016) concerned the choice of weapons in epee fencing (epee with a smooth or pistol grip). Both surveys involved 40 Ukrainian fencing coaches. Their average experience was almost 15 years.

The next stage of our research included the development and implementation of several technical devices. The first one, the "TTT" simulator (Briskin, Pityn, Zadorozhna, \& Smyrnovsky, 2014), was intended for enhancing the level of specialized technical and tactical skills of fencers, and improvement of tactical thinking and specific knowledge (Figure 1).

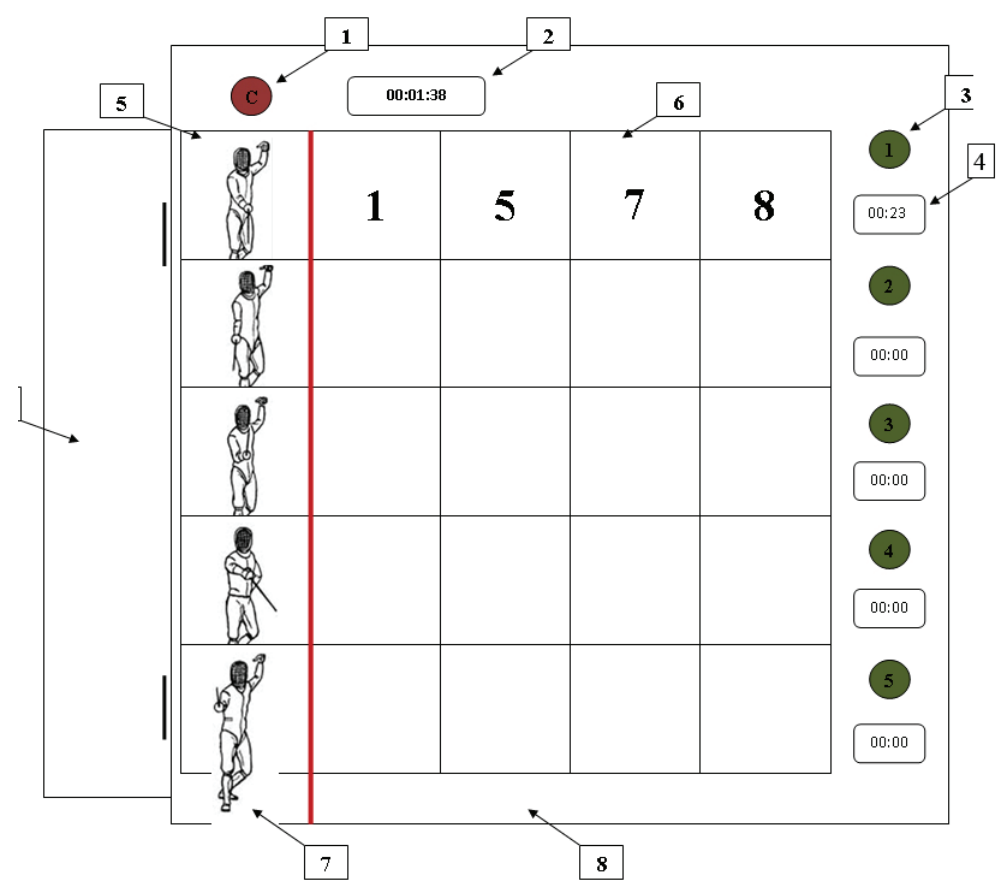

Legend: 1-The start button for a complex of tasks; 2-An indicator of the total execution time of complex tasks; 3-Stop button for completed tasks (each individually, only); 4-The time in the task (for each individual, only); 5-An image that is specified for the job (one for each task); 6-The image that selected by the athlete to respond to the task (one for each task); 7-Taskbar (estimated at 5 tasks images); 8-panel responses (generated by four possible answers to each of the five tasks); 9-The cover of the taskbar that lets you prevent premature perception of information from images

Figure 1. "TTT" Simulator 
The "TTT" Simulator is a vertical platform with a taskbar (estimated at 5 tasks), the cover (which enables preventing premature perception information from images), panel of responses (generated for four possible answers to each of the five tasks), button to start a complex of tasks, an indicator of the total execution time a complex of tasks, a stop button for completed tasks (for each separately, only 5), time indicator of the task (for each separately, only 5). There are two sets of cards, one of which contains intellectual developmental tasks of technical, tactical and theoretical training in fencing, and the second the answers to them. The basis of the use of simulator is the assigned consistent solution of five intellectual tasks by choosing the correct options. The device can be used for a single training exercise or set of exercises in different types of weapons in fencing in the programmes of the Olympics Games and Paralympics Games. It could also be used for the control of theoretical, technical, and tactical preparedness of fencers. However, in our research, it was used only for their improvement.

The second device, "Cube" (Briskin et al., 2014), was aimed at the control of technical and tactical preparedness of fencers by the use of a modular cube with sets of vertical rails and mobile roller targets, which were able to change location according to opponent's parameters (Figure 2). The fencer receives from the coach an algorithmic task that entails successively performing pricks in different sectors of the device that are located in line with the anthropometric characteristics and style of the opponent. The proposed device takes into account the anthropometric characteristics of opponents, bring the terms of training to conditions of real competitive activities, and controlling the technical and tactical preparedness of athletes.

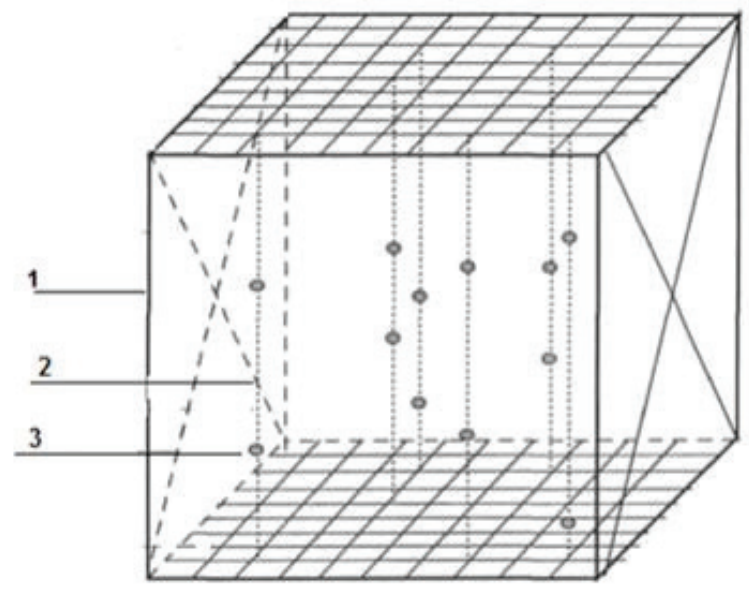

Legend: 1 - Prefabricated cube; 2 - Vertical guides; 3 - Ball targets

Figure 2. "Cube" (Device for technical and tactical training of fencers)

The third device - "Device for the technical training of fencers" - was designed to develop the technical skills of fencers based on improving the specialized feeling of the weapon (Briskin et al., 2014). The device is a metal cylinder that can be moved by the blade and fixed with the screwclamp if it be necessary to regulate the centre of mass of the weapon. On the base (cylinder), four multidirectional cores (tubes) with the length $120 \mathrm{~mm}$, outer diameter $5 \mathrm{~mm}$ and an angle of $90^{\circ}$ are mounted. At the proximal end of the core (tube), the weighting compounds of different weights are attached, which are selected according to age, gender and skills of fencers (Figure 3).

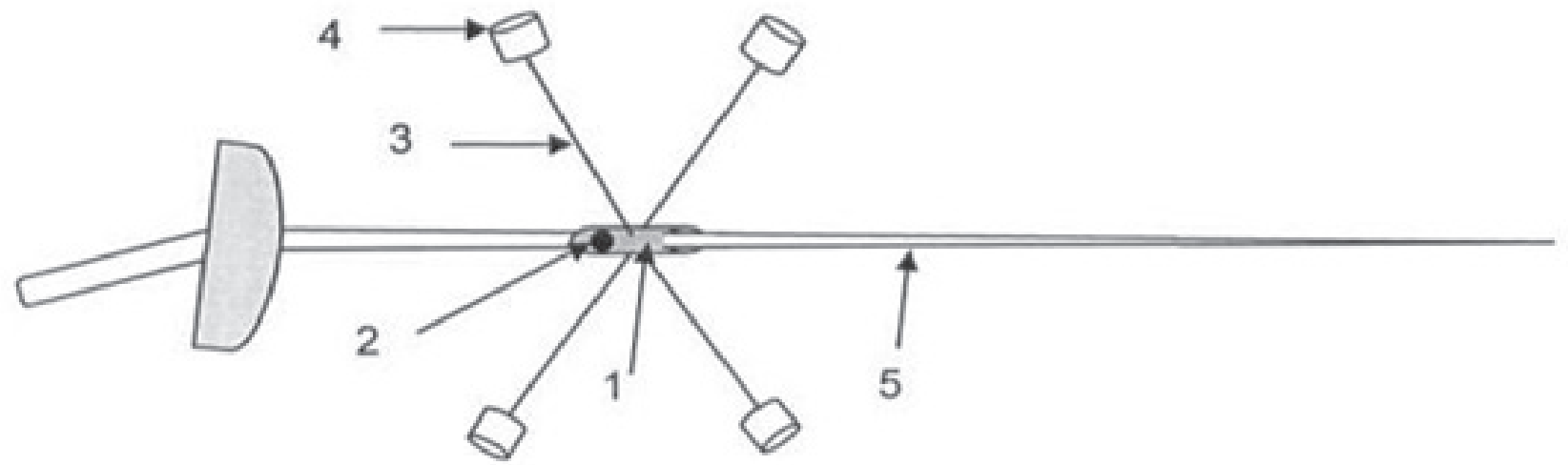

Legend: 1 - Metal cylinder; 2 - The hole for the blade; 3 - The tube of weighting compound; 4 - Weighting compound; 5 - The blade

Figure 3. Device for technical training of fencers

To verify the effectiveness of those devices, two experiments at four fencing clubs in Lviv, Ukraine were held. The first one (01.02.2013-20.12.2013) involved 52 young epee and foil fencers (age 11-15 years). They were divided into two groups: experimental $(n=27)$ and control $(n=25)$. The experimental group used the developed devices for technical, tactical, and 
theoretical preparedness; the control group used traditional means of technical, tactical, and theoretical training. The level of theoretical preparedness of athletes was determined using the author's questionnaire (Briskin et al., 2014), which included five blocks of questions. The observation of athletes' preparedness (the level of knowledge) was measured using the author's questionnaires before and after the experiment.

The second experiment was carried out to test the experimental programme for differentiation of the epee fencers' technical and tactical training, taking into account the ways of weapon control (the use of a pistol grip or a French one). It involved 45 epee fencers, divided into three groups (age 11-15 years), two of which were experimental, while the third group was a comparison one (control group). The first experimental group included epee fencers who applied the weapon with a French grip, whereas the second experimental group used the weapon with a pistol grip. Fencers in both experimental groups used a "Device for the technical training of fencers" to develop their technical and tactical preparedness. The third comparison group involved other fencers, whose method of weapon handling was not taken into account. They used traditional means of technical and tactical training. To estimate the efficiency of the programme, a special device for technical and tactical training of fencers ("Cube") was used. The mea- surement was carried out at the beginning and at the end of the experiment.

\section{Statistical analysis}

Methods of mathematical statistics were used to study the results of the research. In particular, the average arithmetic mean square deviation was calculated. Student's t-test (for calculating the results of the first experiment), Wilcoxon signedrank test, and Mann-Whitney U-test (for calculating the results of the second experiment) were also used.

\section{Results}

The devices described above ("TTT", "Cube", and "Device for technical training of fencers") were testified during pedagogical experiments. The results of pedagogical experiments illustrated that the use of such multi-functional devices is more effective than traditional means.

The results of the first experiment are shown in Table 1. For determining of the statistical significance of data before and after the experiment, we used Student's t-test. It was revealed that before the experiment there was no statistical difference between experimental and control groups $(\mathrm{p}>0.05)$ within all informational blocks. After the experiment, the significant difference in both groups was at the 0.05 level.

Table 1. Indicators of theoretical preparedness within different informational blocks at the end of the first pedagogical experiment in experimental $(\mathrm{N}=27)$ and control $(\mathrm{N}=25)$ groups

\begin{tabular}{|c|c|c|c|c|c|c|c|}
\hline $\begin{array}{c}\text { variables (Informational } \\
\text { block) }\end{array}$ & Group & $\begin{array}{c}\text { Before } \\
\text { experiment }\end{array}$ & p* & $\begin{array}{c}\text { After } \\
\text { experiment }\end{array}$ & $\mathbf{p}^{* *}$ & Increase, \% & $\mathbf{p}^{* * *}$ \\
\hline \multirow{2}{*}{ "History of fencing" } & EG & $4.1 \pm 2.1$ & \multirow{2}{*}{$>0.05$} & $8.5 \pm 1.0$ & \multirow{2}{*}{$<0.05$} & 107.3 & $<0.05$ \\
\hline & CG & $4.3 \pm 2.3$ & & $5.1 \pm 2.2$ & & 18.6 & $<0.05$ \\
\hline \multirow{2}{*}{ "Competitive activity" } & EG & $6.0 \pm 2.0$ & \multirow{2}{*}{$>0.05$} & $8.9 \pm 0.6$ & \multirow{2}{*}{$<0.05$} & 48.3 & $<0.05$ \\
\hline & CG & $5.6 \pm 2.0$ & & $5.2 \pm 2.2$ & & -7.1 & $<0.05$ \\
\hline \multirow{2}{*}{$\begin{array}{l}\text { "Technique and tactics of } \\
\text { fencing" }\end{array}$} & EG & $3.3 \pm 1.6$ & \multirow{2}{*}{$>0.05$} & $8.1 \pm 1.1$ & \multirow{2}{*}{$<0.05$} & 145.5 & $<0.05$ \\
\hline & CG & $5.0 \pm 2.0$ & & $5.8 \pm 2.1$ & & 16.0 & $<0.05$ \\
\hline \multirow{3}{*}{$\begin{array}{l}\text { "Fundamentals of the } \\
\text { theory and methodology of } \\
\text { training of athletes" }\end{array}$} & EG & $3.2 \pm 2.2$ & \multirow[b]{2}{*}{$>0.05$} & $7.3 \pm 1.4$ & \multirow[b]{2}{*}{$<0.05$} & 128.1 & $<0.05$ \\
\hline & CG & $3.8 \pm 1.7$ & & $4.2 \pm 2.0$ & & 10.5 & $<0.05$ \\
\hline & EG & $4.7 \pm 3.2$ & & $8.1 \pm 1.3$ & & 72.3 & $<0.05$ \\
\hline \multirow[t]{2}{*}{ “Olympism” } & & & $>0.05$ & & $<0.05$ & & \\
\hline & CG & $5.3 \pm 2.5$ & & $5.3 \pm 1.9$ & & 0.0 & $<0.05$ \\
\hline
\end{tabular}

Legend: $E G$ - experimental group; CG - control group; $\mathrm{p}^{*}$ - significant difference at the 0.05 level between EG and CG before experiment; $\mathrm{p}^{* *}$ - significant difference at the 0.05 level between EG and CG after experiment; $p^{* * *}$ - significant difference at the 0.05 level inside the groups

According to the results of the first pedagogical experiment, the growth of knowledge in the experimental group within different information blocks ranged from 48.3 to $145.5 \%(p<0.05)$. The most significant growth of those levels was within the information block "Technique and tactics of fencing" at $145.5 \%$. In the control group, the positive growth of the theoretical preparedness was only available in the blocks "History of fencing", "Technique and tactics of fencing", and "Fundamentals of the theory and methodology of training of athletes", ranging from 10.5 to $18.6 \%(\mathrm{p}<0.05)$. It should be mentioned that the level within the information block "Olympism" remained constant, while within the block "Competitive activity" it decreased by $7.1 \%(\mathrm{p}<0.05)$. The greatest increase in the theoretical preparedness in the control group was recorded within the information block "History of fencing", by $18.6 \%(\mathrm{p}<0.05)$. The results of the first experiment illustrated that author's device "TTT" was more effective for improvement of sportsmen's skills (level of knowledge) within all informational blocks, while traditional means were useful only for three blocks ("History of fencing", "Technique and tactics of fencing", and "Fundamentals of the theory and methodology of training of athletes"). Moreover, the increase in the level of knowledge was higher in the experimental group.

During the second pedagogical experiment, the "Device for the technical training of fencers" and "Cube" were used. The first was used for the development of technical and tactical preparedness of fencers, while the second for its estimation. For determining of statistical significance of data before and after 
experiment, we used the Wilcoxon signed-rank test. Also for determining the statistical significance of data between different groups, we used the Mann-Whitney U-test. As shown in Table 1, the use of author's device allowed increasing the accuracy of technical actions in both experimental groups more than in the control group (significant difference at the 0.01 level). In particular, one of the most significant indicators of the effectiveness of our experimental program were indicators of the technical skills of fencers. In all experimental groups, we have tested the accuracy of simple attacks, the accuracy of avoidance attacks, and the accuracy of attacks with weapon actions. We used such indicators because they are most commonly used by young sportsmen. Tests were held before and after the experiment. Before the experiment, we found no statistically significant differences between results in three experimental groups. After the experiment, all results rose. These data are statistically significant. However, the results of simple attacks had more progress in experimental group 1; attacks with weapon actions had more progress in experimental group 2. In our opinion, such progress is connected with the development of weapon feeling and weapon control skills, which enables athletes to perform the techniques more precisely and faster. These data show that our programme of differentiation of technical and tactical training with account of weapon control is effective.

Table 2. Indicators of technical skills at the beginning and at the end of the second pedagogical experiment in experimental groups EG1 ( $\mathrm{N}=15)$ and EG2 $(\mathrm{N}=15)$, and in the control group $(\mathrm{N}=15)$

\begin{tabular}{ccccc}
\hline Indicators & Groups & $\begin{array}{c}\text { Before experiment (amount } \\
\text { of effective hits in 10 } \\
\text { attempts) }\end{array}$ & $\begin{array}{c}\text { After experiment (amount of } \\
\text { effective hits in 10 attempts) }\end{array}$ & Increase \\
\hline $\begin{array}{c}\text { Accuracy of simple } \\
\text { attacks }\end{array}$ & EG1 & $7.1 \pm 0.6$ & $8.9 \pm 0,8$ & $1.8^{*}$ \\
& EG2 & $7.3 \pm 1.0$ & $8.8 \pm 0.7$ & $1.5^{*}$ \\
$\begin{array}{c}\text { Accuracy of simple } \\
\text { attacks with }\end{array}$ & EG1 & $7.1 \pm 0.9$ & $8.0 \pm 0.92$ & $0.9^{* *}$ \\
avoidance & EG2 & $6.7 \pm 0.6$ & $8.8 \pm 0.8$ & $2.1^{*}$ \\
Accuracy of attacks & EG1 & $6.5 \pm 1.0$ & $8.8 \pm 0.8$ & $2.3^{*}$ \\
with weapon actions & EG2 & $6.7 \pm 0.8$ & $7.9 \pm 0.96$ & $1.2^{* *}$ \\
\hline
\end{tabular}

Legend: * significant difference at the 0.01 level; ** - significant difference at the 0.05 level; EG1 - experimental group 1; EG2 - experimental group 2; CG - control group

\section{Discussion}

Analysis of the relevant scientific literature illustrates that some research studies were aimed at the development and experimental implementation of different devices for boxers and fencers. Among them: the "Spuderg simulator" by Savchin (2003), the computer programme "Analysis and modeling of competitive activity of fencers" by Shevchuk (2009), the "Spartak" fighting simulator by Velychenko and Zherdzinsky (2017), "A device for evaluating some of the special physical skills of the boxer" by Saenko et al. (2011), and "Tyshler's Simulator (TTD)" by Tyshler and Ryzhkova (2010). In our opinion, the disadvantage of those methods is that they could be used only for the improvement of the individual aspects of preparedness, and did not provide integral control over the technical, tactical, special physical, and psychophysiological aspects of the preparedness of martial arts. Moreover, their use does not involve the acquisition of specific knowledge of sports theory by athletes and the fulfilment of tasks in the conditions of counteracting the opponent in real time. That is why we have presented several devices aimed not only for the improvement of different aspects of preparedness, but also for their control.

To testify the effectiveness of developed devices, two pedagogical experiments were used. During the first one, fencers of both groups studied information on five blocks: "History of fencing", "Competitive activity", "Technique and tactics", "Fundamentals of the theory and methodology of training", and "Olympism". However, the experimental group used the "TTT" simulator while the control group used traditional means. The use of the "TTT" simulator enabled increasing the sportsmen's level of knowledge at levels of $48.3 \%-145.5 \%$ $(\mathrm{p}<0.05)$. Such progress could be explained by the fact that they studied a greater amount of information of different directions, quickly analysed it and learn to use it in situations that simulate the conditions of competitive activity (the lack of time and conflict interaction). It should be mentioned that this approach to improving theoretical preparedness was not used in other research studies.

The idea of the second pedagogical experiment was to demonstrate that there should be a difference in the training programmes for sportsmen who apply the weapon with a French (smooth) or with a pistol grip. None of the previous research studies considered such an opportunity. For that purpose, in our program, we used a special device for the development of technical skills and weapon feeling. The results of our research illustrated that in the experimental group 1, the indicators of the test for the accuracy of the hits in performing simple attacks and attacks with avoidance are significantly higher than in the experimental group $2(\mathrm{p}<0.01)$, and the control group; the results of the test for the accuracy of hits in the course of attacks with weapon actions are also significantly higher in experimental group $2(\mathrm{p}<0.01)$.

Thus, the results of both pedagogical experiments illustrated that the use of such multi-functional devices is more effective than using traditional means. Moreover, all devices could be modified and used in other kinds of martial arts (judo, wrestling, taekwondo, boxing, etc.). 


\section{Acknowledgements}

There are no acknowledgements.

\section{Conflict of Interest}

The authors declare that there are no conflicts of interest.

Received: 24 June 2019 | Accepted: 24 September 2019 | Published: 01 February 2020

\section{References}

Alekseenko, V.A. (1970). Studies of motor reactions in fencers in the process of training and justification of the selection of special exercises to monitor their improvement. Doctoral Dissertation. Moscow: Russian State University of Physical Culture, Sports, Youth and Tourism. [in Russian].

Briskin, Yu., Pityn, M., Zadorozhna, O., \& Smyrnovskyy, S. (2014). Device for technical training fencers: patent. 87020 Ukraine. MPK A63B 69/02 (2006.01). № a201311306; claimed. 23.09.2013; published. 27.01.2014 bull. № 2. [in Ukrainian].

Briskin, Yu., Pityn, M., Zadorozhna, O., \& Khomiak, I.I. (2018). Inventor, patent holder. Method to improve and integrate control of preparedness of martial arts. Patent Ukraine №12899: 2018 Oct. 10. [in Ukrainian].

Briskin, Yu., Zadorozhna, O., Perederiy, A., Pityn, M., \& Sydorko, O. (2018) Team composition in epee fencing which accounts for sportsmen's individual performance. Journal of Physical Education and Sport, 273 1863-1870. doi:10.7752/jpes.2018.s4273

Bychkov, Y. (2006). Coach in the fencing lesson: Physical education. [in Russian].

Chen, T.L-W., Wong, D.W-C., Wang, Y., Ren, S., Yan, F., \& Zhang, M. (2017) Biomechanics of fencing sport: A scoping review. PLoS ONE, 12(2), e0171578. https://doi.org/10.1371/journal.pone.0171578

Harmenberg, J. (2007). Epee 2.0: The Birth of New Fencing Paradigm. SK SwordPlay Books, N.Y.

Harmenberg, J., Ceci, R., Barvestad, P., Hjerpe, K., \& Nyström, J. (1991) Comparison of different tests of fencing performance. International Journal of Sports Medicine, 12(6), 573-576. doi.org/10.1055/s-2007-1024736

Jean-Marie, S. (2008). The Olympic Games in Beijing. Strategy and Technique. Escrime Internationale, FIE, 4, 19-28.

Johnson, J. (2016). Enhancing Taekwondo Pedagogy through Multiple
Intelligence Theory. Ido Movement for Culture. Journal of Martial Arts Anthropology, 16(3), 57-64, doi: 10.14589/ido.16.3.7.

Johnson, J., \& Kang, H.J. (2018), Hapkido research trends: a review. Ido Movement for Culture. Journal of Martial Arts Anthropology, 18(3), 42-50. doi: 10.14589/ido.18.3.7.

Kriventsova, I., Iermakov, S., Bartik, P., Nosko, M., \& Cynarski, W.J. (2017). Optimization of student-fencers' tactical training. Ido Movement for Culture. Journal of Martial Arts Anthropology, 17(3), 21-30. doi: 10.14589/ ido.17.3.3

Lisitsyn, V.V. (2015). Technical and tactical training of highly qualified female boxers. Doctoral Dissertation. Moscow: Russian State University of Physical Culture, Sports, Youth and Tourism. [Russian].

Matveev, L. (2001). The general theory of sport and its applications. St.Petersburg, Lan', 310-334. [in Russian].

Pityn, M., Briskin, Y., Perederiy, A., Galan, Y., Tsyhykalo, O., \& Popova, I. (2017). Sport specialists attitude to structure and contents of theoretical preparation in sport. Journal of Physical Education and Sport, 17, 988-994. doi:10.7752/jpes.2017.s3152

Ryzhkova, L.G. (2014). Vyibor takticheskoy modeli vedeniya boya v ekstremalnyih usloviyah sorevnovaniy u fehtovalschikov vyisshey kvalifikatsii. Ekstrem. deyatelnost cheloveka, 2, 123-125 [in Russian].

Saenko, O.V., Ivanov, V.I., \& Stepanenko, S.V. (2011). Inventor, patent holder. A device for evaluating some of the special physical skills of the boxer. Patent Ukraine №62607: 2011 Sep. 12.

Savchin, M. (2003). Training of the boxer and its diagnostics. Nora-print. [in Ukrainian].

Shevchuk, E. (2009). Computer program "Analysis and modeling of competitive activity of fencers" as a means and method of preparing for competitions. Chernigiv, 69, 311-315 [in Ukrainian].

Tupeev, Yu.V., \& Bojko V.F. (2010). Analyzes of methodological approaches during technique studying in sports wrestling. Fizicheskoe vospitanie studentov: nauchnyj zhurnal, 3, 116-121. [in Russian].

Tyshler, D., \& Ryzhkova, L. (2010). Fencing. Technical and tactical and functional training. Academic project. [in Russian].

Velychenko, Y.V., \& Zherdzinsky, I.A. (2017). Inventor, patent holder. Fighting simulator “Spartak". Patent Ukraine №119649: 2017 Sep. 27. 